\title{
The impact of patient-specific instrumentation on unicompartmental knee arthroplasty: a prospective randomised controlled study
}

\author{
Abtin Alvand ${ }^{1}\left({ }^{10} \cdot\right.$ Tanvir Khan $^{1} \cdot$ Cathy Jenkins $^{2} \cdot$ Jonathan L. Rees $^{1} \cdot$ \\ William F. Jackson ${ }^{2} \cdot$ Christopher A. F. Dodd $^{2} \cdot$ David W. Murray $^{1} \cdot$ Andrew J. Price $^{1}$
}

Received: 16 May 2017 / Accepted: 14 August 2017 / Published online: 22 August 2017

(C) The Author(s) 2017. This article is an open access publication

\begin{abstract}
Purpose Patient-specific instrumentation (PSI) has been proposed as a means of improving surgical accuracy and ease of implantation during technically challenging procedures such as unicompartmental knee arthroplasty (UKA). The purpose of this prospective randomised controlled trial was to compare the accuracy of implantation and functional outcome of mobile-bearing medial UKAs implanted with and without PSI by experienced UKA surgeons.

Methods Mobile-bearing medial UKAs were implanted in 43 patients using either PSI guides or conventional instrumentation. Intra-operative measurements, meniscal bearing size implanted, and post-operative radiographic analyses were performed to assess component positioning. Functional outcome was determined using the Oxford Knee Score (OKS).

Results PSI guides could not be used in three cases due to concerns regarding accuracy and registration onto native anatomy, particularly on the tibial side. In general, similar component alignment and positioning was achieved using the two systems (n.s. for coronal/sagittal alignment and tibial coverage). The PSI group had greater tibial slope $(p=0.029)$. The control group had a higher number of optimum size meniscal bearing inserted (95 vs 52\%; $p=0.001$ ). There were no differences in OKS improvements (n.s).
\end{abstract}

Abtin Alvand

abtin.alvand@ndorms.ox.ac.uk

1 Nuffield Department of Orthopaedics, Rheumatology and Musculoskeletal Sciences, Botnar Research Centre, University of Oxford, Old Road, Oxford OX3 7LD, UK

2 Nuffield Orthopaedic Centre, Windmill Road, Headington, Oxford OX3 7LD, UK
Conclusion Component positioning for the two groups was similar for the femur but less accurate on the tibial side using PSI, often with some unnecessarily deep resections of the tibial plateau. Although PSI was comparable to conventional instrumentation based on OKS improvements at 12 months, we continue to use conventional instrumentation for UKA at our institution until further improvements to the PSI guides can be demonstrated.

Level of evidence Therapeutic, Level I.

Keywords Unicompartmental knee arthroplasty · Patientspecific instrumentation $\cdot$ Knee $\cdot$ Arthroplasty

\section{Introduction}

The Oxford unicompartmental knee arthroplasty (UKA) is the most commonly performed UKA in England, accounting for $62 \%$ of all those performed [8]. Numerous studies have demonstrated excellent long-term survival rates in large cohorts [23, 28, 29]. However, the survival rate of the UKA in joint registries is lower than that achieved in large cohort studies [8]. Registry data have highlighted the role of experience and surgical caseload in determining successful outcomes after UKA, demonstrating better results for UKAs performed by high-volume surgeons in high-volume centres $[2,21]$. Technical difficulty of UKA is thought to contribute significantly to the variations observed in surgical performance and results $[9,10,14,22,23,30,32,35]$. The implication is that those aiming to undertake UKA must be adequately trained and perform a certain number of cases annually. In addition, particularly for inexperienced and lowvolume surgeons, there is a need for technological innovations to improve surgical accuracy. A technological tool that has recently received significant attention is patient-specific 
instrumentation (PSI) for knee arthroplasty [1, 20, 33]. This uses 3-D imaging techniques (MRI or CT) and rapid prototyping technology to produce patient-specific guides for making the femoral and tibial bone resections. PSI systems aim to improve accuracy of implant positioning in addition to the reduction of fat embolism risk, instrument inventory, and operative time [3, 7, 25, 31, 37]. The PSI system developed for the Oxford UKA is the "Signature" system (Zimmer Biomet Inc, Warsaw, IN, USA). It aims to simplify and improve the accuracy of surgical implantation, which is important in determining the outcome of the procedure $[5,13]$. If this PSI system works reliably, it is likely to be particularly useful for low-volume UKA surgeons. However, before this can be done, experienced surgeons should assess the system's reliability. Recent case-series and laboratorybased experiments have demonstrated that PSI technology can improve component positioning during UKA surgery $[11,15,18,36]$. However, the effect of this technology has received little attention in randomised studies.

Before inexperienced surgeons use such technology, experienced UKA surgeons must evaluate its safety and reliability in order to ensure that no harm comes to patients. The purpose of this prospective randomised controlled trial (RCT) was therefore to compare the accuracy of implantation and functional outcome of mobile-bearing medial UKAs implanted with and without PSI by experienced UKA surgeons.

\section{Materials and methods}

This single-centre parallel-design RCT was conducted between 2012 and 2014. Ethical approval was obtained, and the trial was registered with the United Kingdom National Research Ethics Service committee (REC reference: 11/H0605/1) and the hospital review board. The study was registered at ClinicalTrials.gov (NCT02748096). Four expert OUKA surgeons (DWM, CAFD, AJP, and WFMJ) performed all of the procedures in this study. These surgeons had previously performed a total of ten Oxford UKA procedures using this PSI system and so were familiar with the technique. Patients who were being placed on the waiting list for a medial OUKA and met the entry criteria for the trial, were asked whether they would be willing to receive further information about participation in the study. They were provided with a study information leaflet that they could read in their own time. A member of the research team (AA) subsequently contacted the patients in order to determine whether they would agree to take part in the study and enrolled them onto the study.

Inclusion criteria were standard for medial OUKA:

- Both cruciate ligaments functionally intact.
- Full-thickness cartilage in the lateral compartment.

- Correctable intra-articular varus deformity (based on clinical assessment).

- Full-thickness cartilage loss in the medial compartment.

Exclusion criteria were as follows:

- Contra-indication for MRI.

- All forms of inflammatory arthritis.

The flow of patients through the trial is presented in Fig. 1. Patients were randomised to either PSI or Conventional Instrumentation (CI) group by one of the investigators (AA). The Oxford Microplasty instrumentation was used to implant all UKAs in the CI group. There were 23 patients ( 23 knees) in the PSI group and 22 patients (22 knees) in the CI group. Randomisation was performed using sealed opaque envelopes. Blinding of the operating surgeons and patients was not possible owing to the surgeon needing to confirm the PSI plans, and the patients undergoing pre-operative MRI scans. PSI group patients underwent an MRI scan using the protocol outlined by the PSI manufacturers to plan development of the PSI guides. The preliminary plan indicating prosthesis size, positioning, alignment, and proposed bone resection levels was reviewed by the surgeons who accepted the default pre-operative plans unless gross errors were present. The patient-specific cutting guides were then manufactured and sent for sterilisation.

\section{Operative technique}

All patients received a mobile-bearing medial OUKA via a minimally invasive approach and high thigh tourniquet. Intra-operatively, the bone cuts were made through the PSI guides without the use of any intra- or extramedullary instrumentation on the femoral side but with a tibial extramedullary guide for some cases. The subsequent milling process and all soft tissue balancing were performed manually in the standard fashion. In cases where the surgeon felt that the PSI guides did not fit appropriately, the conventional instrumentation was utilised. This situation occurred during three cases. Post-operatively, the need to have a blood transfusion, and the change haemoglobin levels were also recorded. Oxygen saturation levels over the first $24 \mathrm{~h}$ postsurgery were also recorded. Screened anteroposterior (AP) and lateral (LA) post-operative radiographs were performed prior to discharge. Patients attended the physiotherapy ward discharge clinic at 6 weeks. A further clinical review was performed at 12 months at which point Oxford Knee Scores (OKS) were recorded. 


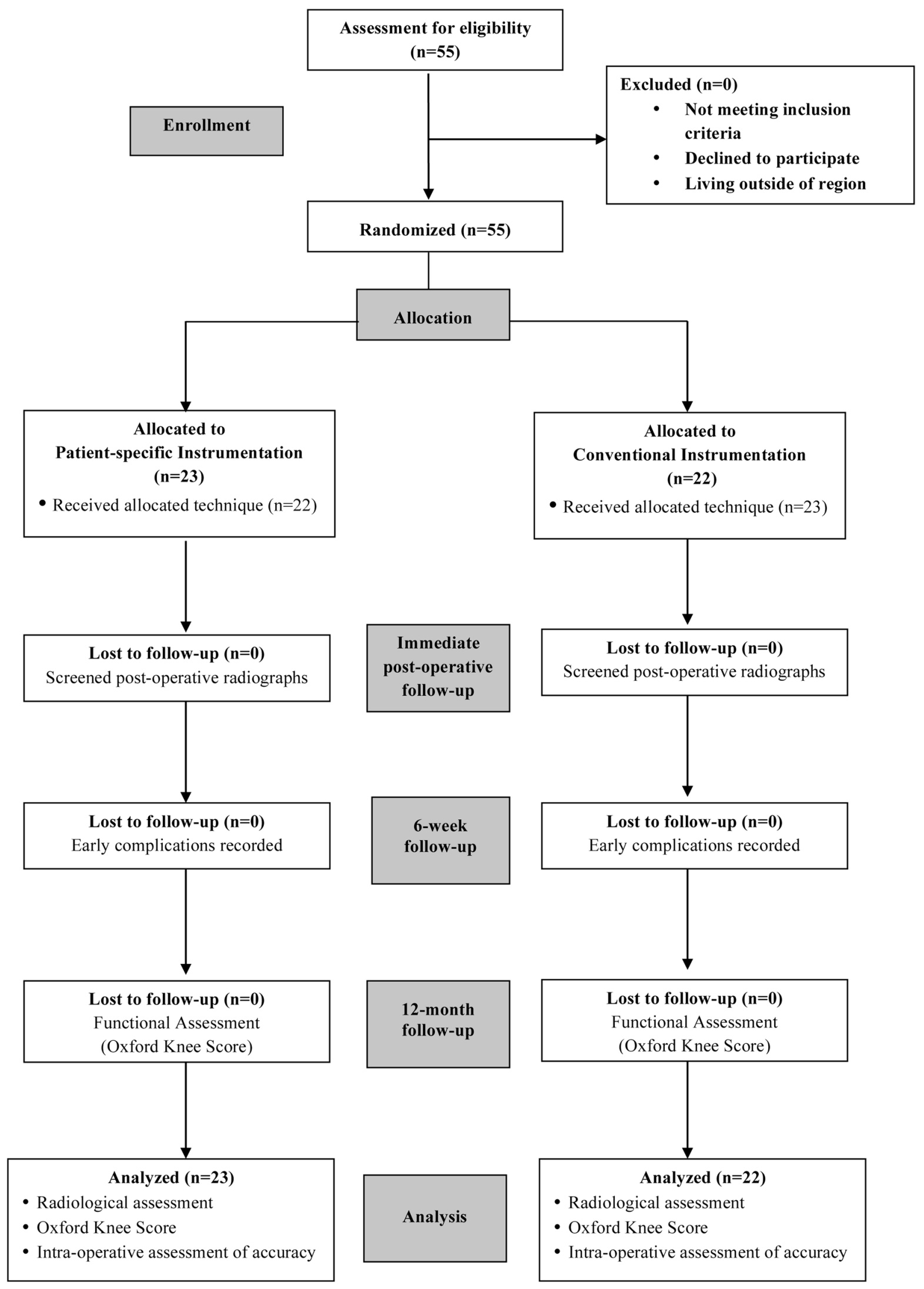

Fig. 1 A consolidated standards of reporting trials (CONSORT) diagram showing the flow of patients in the study 


\section{Outcome measures}

Primary outcome measure: radiological assessment of component positioning

This was performed on screened post-operative radiographs, according to the parameters proposed by developers of the OUKA [12]. These describe optimum ranges for alignment and fit of the components (Table 1). These parameters were measured by two independent (blinded) assessors (AA and TK) using custom software developed in Matlab (v.7.0, The MathsWork Inc., MA, USA). The radiographs were converted from DICOM to JPEG files before analysis. For measurements of distance in millimetres, the software used a conversion factor calculated by dividing the known diameter of the femoral component (provided by the manufacturer) by the diameter of a circle fitted to the component in pixels. For the prosthesis component alignment measurements (i.e. angles), the software uses points on the diaphysis and metaphysis of the femur and tibia to map out the vertical axes of the tibia and femur. Selecting additional points on the femoral and tibial components of the OUKA enables the software to calculate the sagittal and coronal alignment of the prosthesis. These radiographic parameters were measured twice on two separate days, in order to determine inter-observer and test-retest reliability. The intra-class correlation coefficient (ICC) for all the radiographic measurements undertaken using this system was excellent with all measured parameters having an ICC $>0.8$.

\section{Secondary outcome measures}

\section{Assessment of functional outcome}

This was determined using the pre-operative and 12-month follow-up OKS (with the maximum possible score of 48).
The OKS is a validated 12-item questionnaire that addresses pain and functional disability in relation to knee problems [24].

The remaining outcome measures were used to further evaluate the efficiency and safety of the PSI system.

Intra-operative assessment of surgical accuracy

- Correspondence between the implanted and planned component sizes.

- The need to perform a horizontal tibial "re-cut".

- Tracking of the meniscal bearing (measured as the distance from bearing to the metal upright of the tibial component in flexion and extension).

- Size of the meniscal bearing inserted (optimum bearing size considered as 3 or $4 \mathrm{~mm}$ ).

\section{Statistical analysis}

The sample size was calculated from a previous study that used similar radiological assessments to compare OUKAs performed using conventional instrumentation, with those performed using computer navigation [16]. In this study, the standard deviation of the tibia varus/valgus angle for the control group was $3.6^{\circ}$. Assuming a minimum clinically important difference of $3^{\circ}$, the standard mean difference would be 0.8 . Hence with a power of 0.8 and significance level of 0.05 , a total sample size of 44 patients ( 22 in each group) was required.

The Shapiro-Wilk test showed that all data, except "bearing alignment", were normally distributed. Parametric tests were applied to normally distributed data. The independent group $t$ test was used to compare group demographics, radiographic parameters, $\mathrm{OKS}$, and operative time. The
Table 1 Optimum ranges for the radiographic parameters used to assess implant positioning and alignment

\begin{tabular}{ll}
\hline Radiographic parameter & Optimum position \\
\hline $\begin{array}{l}\text { Femoral component: varus/valgus angle } \\
\text { (AP radiograph) }\end{array}$ & $<10.0^{\circ}$ varus to $<10.0^{\circ}$ valgus \\
$\begin{array}{l}\text { Femoral component: flexion/extension angle } \\
\text { (LA radiograph) }\end{array}$ & $15.0^{\circ}$ flexion to $<0^{\circ}$ extension \\
$\begin{array}{l}\text { Tibial component: varus/valgus angle } \\
\text { (AP radiograph) }\end{array}$ & $<5.0^{\circ}$ varus to $<5.0^{\circ}$ valgus \\
Tibial component: posterior tilt (slope) angle & Within $\pm 5.0^{\circ}$ of the $0^{\circ}$ baseline ("Baseline" \\
(LA radiograph) & $\begin{array}{l}\text { taken as } 7.0^{\circ} \text { posterior tilt but this is recorded } \\
\text { as } 0^{\circ} \text { ) }\end{array}$ \\
Tibial component: medial fit & Flush or $<2.0 \mathrm{~mm}$ overhang \\
(AP radiograph) & Flush or $<2.0 \mathrm{~mm}$ overhang \\
Tibial component: anterior fit & \\
(LA radiograph) & Flush or $<5.0 \mathrm{~mm}$ underhang \\
Tibial component: posterior fit & \\
(LA radiograph) & \\
\hline
\end{tabular}


Pearson Chi-square test was used to compare "radiographic parameter outliers" and "bearing sizes". The Mann-Whitney $U$ test was used to compare "bearing alignment". The inter-observer and test-retest reliability of the radiographic parameters was assessed using the ICC. Statistical analyses were performed with IBM SPSS Statistics version 22 (Chicago, IL, USA). A $p$ value $<0.05$ was considered statistically significant.

\section{Results}

\section{Participant demographics}

The groups were evenly matched in terms of age, sex, American Society of Anesthesiologists (ASA) grade, and body mass index (BMI) (Table 2).

\section{Primary outcome measure: radiological assessment of component positioning}

No patients were lost to follow-up. The ICCs for all radiographic parameters were greater than 0.80 indicating high test-retest and inter-observer reliability. The mean radiographic parameter values are presented in Table 3 . There were no statistical differences in component positioning between the groups, except for the "posterior tilt" of the tibial component. The proportion of cases that were positioned outside the optimum ranges (outliers) are summarised in Table 4. There was no significant difference between the numbers of outliers in the two groups.

\section{Secondary outcome measures}

\section{Assessment of functional outcome}

Table 5 summarises the mean OKS results for the two groups. There was no significant difference in the mean OKS improvements between the two groups.

\section{Intra-operative assessment of surgical accuracy}

The PSI guides could not be used for 3 (13\%) patients, as they would not fit onto the patient's native anatomy. This occurred for both the femoral and tibial guides in one patient, and the tibial guides only for two patients. With regard to the planning of implant sizes, 21 (91\%) of the femoral components implanted corresponded to the sizes that were planned pre-operatively. On the other hand, only $11(48 \%)$ of the tibial components implanted corresponded to the sizes that were planned pre-operatively.
Table 2 Summary of the study subjects' demographics and operative time

\begin{tabular}{llll}
\hline Demographic & $\begin{array}{l}\text { Patient-specific instru- } \\
\text { mentation }(n=23)\end{array}$ & $\begin{array}{l}\text { Conventional instrumen- } \\
\text { tation }(n=22)\end{array}$ & $p$ value \\
\hline Mean age (range) in years & $66.9(52.2-77.1)$ & $68.2(51.0-88.2)$ & n.s. \\
Sex (M:F) & $10: 13$ & $13: 9$ & n.s. \\
Median ASA (range) & $2(1-3)$ & $2(1-3)$ & n.s. \\
Mean body mass index (range) & $29.8(23.8-40.3)$ & $31.8(22.2-39.5)$ & n.s. \\
Mean operative time (range) in minutes & $75.3(53.0-90.0)$ & 63.5 min $(50.0-82.0)$ & $0.001^{* *}$ \\
\hline
\end{tabular}

ASA American Society of Anaesthesiologists grade

** Statistically significant difference

Table 3 Summary of the radiographic parameters in the patient-specific instrumentation and conventional instrumentation groups

\begin{tabular}{|c|c|c|c|}
\hline Radiographic parameter & $\begin{array}{l}\text { Patient-specific instrumentation } \\
\text { Mean (SD) }\end{array}$ & $\begin{array}{l}\text { Conventional instrumentation } \\
\text { Mean (SD) }\end{array}$ & $p$ value (means) \\
\hline Femur: varus/valgus angle & $0.9^{\circ}$ varus $(4.0)$ & $1.8^{\circ}$ varus $(3.0)$ & n.s. \\
\hline Femur: flexion/extension angle & $9.1^{\circ}$ flexion $(3.0)$ & $8.8^{\circ}$ flexion $(4.8)$ & n.s. \\
\hline Tibia: varus/valgus angle & $3.5^{\circ}$ varus $(2.9)$ & $4.0^{\circ}$ varus $(2.1)$ & n.s. \\
\hline Tibia: posterior tilt angle & $1.8^{\circ}$ superior $(2.8)$ & $3.7^{\circ}$ superior $(2.1)$ & $0.029 * *$ \\
\hline Tibia: medial fit & $0 \mathrm{~mm}(1.0)$ & $1.0 \mathrm{~mm}$ underhang (1.3) & n.s. \\
\hline Tibia: anterior fit & $1.0 \mathrm{~mm}$ underhang $(0.9)$ & $1.0 \mathrm{~mm}$ underhang $(0.7)$ & n.s. \\
\hline Tibia: posterior fit & $0 \mathrm{~mm}(0.8)$ & $0 \mathrm{~mm}(0.9)$ & n.s. \\
\hline
\end{tabular}

$S D$ standard deviation

** Statistically significant difference 
Table 4 Proportion of radiographic parameter outliers in the patientspecific instrumentation and conventional instrumentation groups

\begin{tabular}{|c|c|c|c|}
\hline Radiographic parameter & $\begin{array}{l}\text { Patient-specific instrumenta- } \\
\text { tion }(n=23) \\
\text { Number of outliers [\%] }\end{array}$ & $\begin{array}{l}\text { Conventional instrumenta- } \\
\text { tion }(n=22) \\
\text { Number of outliers [\%] }\end{array}$ & $p$ value \\
\hline Femur: varus/valgus angle & $\begin{array}{l}1 \text { (varus) } \\
{[4 \%]}\end{array}$ & None & n.s. \\
\hline Femur: flexion/extension angle & None & $\begin{array}{l}1 \text { (flexed) } \\
{[5 \%]}\end{array}$ & n.s. \\
\hline Tibia: varus/valgus angle & $\begin{array}{l}5 \text { (all varus) } \\
{[22 \%]}\end{array}$ & $\begin{array}{l}6 \text { (all varus) } \\
{[27 \%]}\end{array}$ & n.s. \\
\hline Tibia: posterior tilt angle & $\begin{array}{l}2 \text { ( } 1 \text { superior, } 1 \text { inferior }) \\
{[9 \%]}\end{array}$ & $\begin{array}{l}5 \text { (all superior) } \\
{[3 \%]}\end{array}$ & n.s. \\
\hline Tibia: medial fit & None & $\begin{array}{l}1 \text { (underhang) } \\
\text { [5\%] }\end{array}$ & n.s. \\
\hline Tibia: anterior fit & None & None & NA \\
\hline Tibia: posterior fit & None & $\begin{array}{l}1 \text { (overhang) } \\
{[5 \%]}\end{array}$ & n.s. \\
\hline
\end{tabular}

Comments in brackets indicate the direction of the outliers
Table 5 Pre-operative and 1-year Oxford Knee Score results of the two groups

\begin{tabular}{llll}
\hline $\begin{array}{l}\text { Mean Oxford } \\
\text { Knee Score, OKS } \\
\text { (range) }\end{array}$ & $\begin{array}{l}\text { Patient-specific } \\
\text { instrumentation } \\
(n=23)\end{array}$ & $\begin{array}{l}\text { Conventional } \\
\text { instrumentation } \\
(n=22)\end{array}$ & $p$ value \\
\hline Pre-op OKS & $24.1(12-38)$ & $23.3(10-37)$ & n.s. \\
Post-op OKS & $42.4(21-48)$ & $41.5(26-48)$ & n.s. \\
$\Delta$ OKS & $18.3(4-31)$ & $18.2(5-31)$ & n.s. \\
\hline
\end{tabular}

Table 6 summarises the cases in each group that required a tibial plateau "re-cut" and the results for tracking of the meniscal bearing.

\section{Bearing size implanted}

All but one of the CI group had a size 3 or $4 \mathrm{~mm}$ (i.e. optimum size) meniscal bearing inserted compared with only 12 in the PSI group (Fig. 2). This difference was statistically significant $(p=0.001)$.

\section{Complications}

There were two superficial wound infections (one in each group), which were treated by the patients' family practitioners with oral antibiotics. At the 1-year review, no further complications had occurred and no prostheses had been revised.

\section{Discussion}

The most important finding of this study was that the OUKA PSI system had similar accuracy to conventional instrumentation with regard to femoral component positioning and alignment, but was less accurate for tibial component positioning resulting in unnecessarily deep tibial resections. Although there was no difference in functional outcome between the two cohorts at one year, we conclude that, in the hands of experienced UKA surgeons, the iteration of the PSI system assessed in the current study was not better than current (conventional) instrumentation.

An important finding, which suggests that the PSI was inferior to the conventional system, was that a significantly lower number of cases in the PSI group had the "optimum" bearing size implanted ( 3 or $4 \mathrm{~mm}$; $52 \%$ of the PSI group compared to $95 \%$ of the CI group). The PSI group tended to have thicker bearings, which are associated with higher failure rates in the long term [28]. In addition, we believe that deep resections pose the danger of damaging the deep

Table 6 Proportion of cases in each group that required a tibial plateau "re-cut" and the results for tracking of the meniscal bearing in flexion and extension

\begin{tabular}{|c|c|c|c|}
\hline & $\begin{array}{l}\text { Patient-specific instrumentation } \\
(n=23)\end{array}$ & $\begin{array}{l}\text { Conventional instrumentation } \\
(n=22)\end{array}$ & $p$ value \\
\hline Cases requiring horizontal "re-cut" of the tibial plateau & 3 & 2 & n.s. \\
\hline $\begin{array}{l}\text { Median (and interquartile range) distance between the bearing to } \\
\text { the metal upright of the tibial component wall }\end{array}$ & $\begin{array}{l}\text { Flexion: } 1 \mathrm{~mm}(1-2) \\
\text { Extension: } 2 \mathrm{~mm}(1-2.5)\end{array}$ & $\begin{array}{l}\text { Flexion: } 1 \mathrm{~mm}(1-1.5) \\
\text { Extension: } 1 \mathrm{~mm}(1-2)\end{array}$ & $\begin{array}{l}\text { n.s. } \\
\text { n.s. }\end{array}$ \\
\hline
\end{tabular}


Fig. 2 Bar chart demonstrating the differing bearing sizes implanted in each group

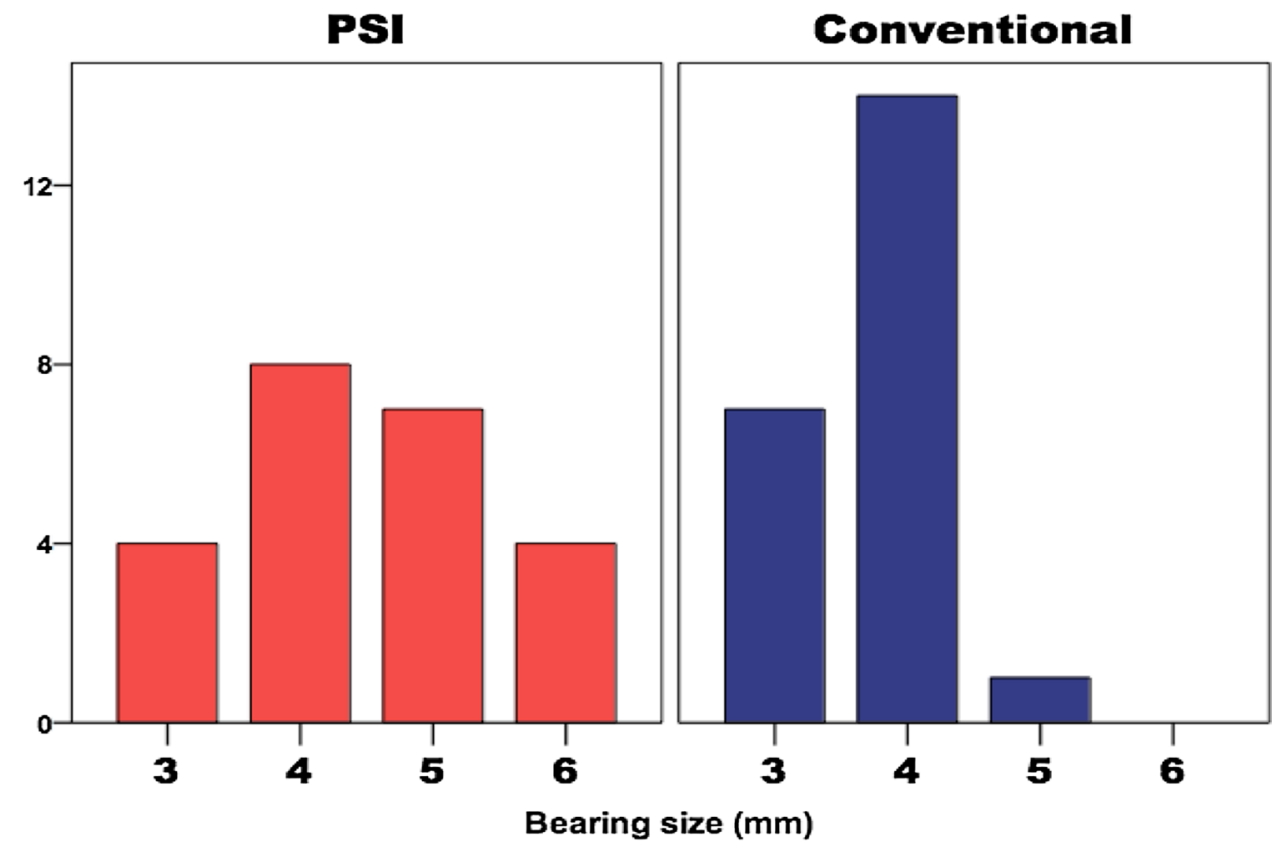

fibres of the medial collateral ligament and the bone may be weakened with an increase in the risk of pain and fracture. Since this study was undertaken, the PSI algorithm has been altered so that the resections are not so deep. Another important finding was that in some cases, the tibial PSI guides did not register adequately on the native tibia. Thus, further work is needed to improve the tibial PSI guides. The unexpected finding of an increased operative time observed in the PSI group could most likely be explained by the fact that the surgeons were intentionally devoting some extra time to evaluating the PSI guides intra-operatively so that they could provide meaningful feedback to the PSI development engineers.

The radiological assessment of component alignment and positioning was based on the recommendations of the OUKA design manual and the literature $[6,13]$. Although no difference was found in the number of outliers between the PSI and CI groups, the use of PSI resulted in improvements in optimum posterior tibial slope and the optimum medial fit of the tibial component. The clinical relevance of these minor improvements is not clear. In contrast to the current study, a laboratory-based study demonstrated that PSI was more accurate than CI and was equivalent to a robot-assisted system [15] and a case-series by Volpi et al. [36]. showed that PSI was "highly accurate in reproducing what the surgeon had planned". However, more recent studies have not been able to replicate these promising early results. A retrospective series of 30 Oxford "Signature" UKAs demonstrated similar radiological outcomes as the present study, and comparable results to standard instrumentation [17]. The authors also reported difficulties with use of the tibial guides. Furthermore, a recent study utilising CT scans to determine the accuracy of component positioning and alignment using the OUKA PSI system found that there was no agreement between the pre-operative plans and the postoperative component alignment for the femoral component angle in the sagittal and axial plane and for the tibial component angle in the coronal plane [34]. Similarly, recent RCTs comparing PSI guides with conventional instrumentation for implanting TKAs have demonstrated either no additional benefit $[19,38]$ or detrimental effects on implant positioning when using PSI [27].

With regard to functional outcome, we found no significant difference in OKS improvement. There is little previous work regarding the effect of PSI on functional outcome, but a case-series by Bell et al. [4] which assessed a different UKA PSI system mirrored our results and demonstrated excellent functional outcome (OKS and Forgotten Joint score) at one year. Only one randomised study has evaluated functional outcome following in UKA, using a different PSI system by using 3-D gait analysis, the SF-12, and the Knee Society Score [26]. This study demonstrated no significant differences at one year between the two groups.

This study had some limitations. Firstly, the surgeons performing the cases were highly experienced OUKA surgeons with extensive previous experience of the CI. These experts are therefore likely to have a very low number (if any) of surgical outliers when using the CI. This potential bias is further amplified by the surgical learning curve associated with the use of the PSI. A concerted effort was made by the surgeons to address this issue by familiarising themselves with the PSI in a previous pilot study. Nevertheless, the previous experience of the surgeons with the conventional instrumentation is very likely to have favoured the CI group 
and hence it would have been difficult to demonstrate more superior surgical accuracy using PSI. Secondly, the radiological assessment was based on coronal and sagittal alignment. Further evaluation of component rotation using CT scans would have been desirable but was limited by resources. Nevertheless, the radiographic parameters were those recommended by the designers of the OUKA and previous studies have validated their use $[6,13]$. The current study was powered to detect important differences in component alignment and positioning. It is likely to have been underpowered for detecting clinically important changes in OKS. However, the rationale for the current study can be justified based on patient safety factors. Finally, the current study did not evaluate the long-term implant survival and risk of revision surgery - a factor that which is key in determining the efficacy of PSI technology. PSI technology is an exciting development that has received significant attention over the past decade. However, further evaluation and improvement of the PSI guides used in the current study are necessary before they can be utilised on a regular basis in day-to-day clinical work.

\section{Conclusion}

The results of this study demonstrate that high-volume OUKA surgeons can achieve similar results, in terms of component alignment and functional outcome when using PSI guides for OUKA. However, intra-operative assessment of the tibial guides by expert OUKA surgeons suggests that although the early "Signature" PSI system design used for this study can safely be used by experienced surgeons, it is not appropriate for inexperienced surgeons.

Acknowledgements The authors would like to thank B. E. Marks and J. Brown for their assistance with this study.

Authors' contribution AA was involved in the study design, patient assessment, data collection, data analysis, and manuscript preparation. TK was involved in the study design, data collection, data analysis, and manuscript preparation. CJ was involved in the data collection, patient assessment, and manuscript preparation. JR was involved in the study design, data analysis, and manuscript preparation. WJ involved in the study design, performed surgeries, and prepared the manuscript. CD involved in the study design, performed surgeries, and prepared the manuscript. DM involved in the study design, performed surgeries, and prepared the manuscript, and AP involved in the study design, performed surgeries, and prepared the manuscript.

\section{Compliance with ethical standards}

Conflict of interest The author or one or more of the authors have received or will receive benefits for personal or professional use from a commercial party related directly or indirectly to the subject of this article. In addition, benefits have been or will be directed to a research fund, foundation, educational institution, or other non-profit organisation with which one or more of the authors are associated.
Funding This study has been supported by the National Institute of Health Research Oxford Biomedical Research Unit.

Ethical approval For this study ethical approval was obtained, and the trial was registered with the United Kingdom National Research Ethics Service committee (REC reference: 11/H0605/1).

Open Access This article is distributed under the terms of the Creative Commons Attribution 4.0 International License (http://creativecommons.org/licenses/by/4.0/), which permits unrestricted use, distribution, and reproduction in any medium, provided you give appropriate credit to the original author(s) and the source, provide a link to the Creative Commons license, and indicate if changes were made.

\section{References}

1. Ast MP, Nam D, Haas SB (2012) Patient-specific instrumentation for total knee arthroplasty: a review. Orthop Clin North Am 43:e17-e22

2. Baker P, Jameson S, Critchley R, Reed M, Gregg P, Deehan D (2013) Center and surgeon volume influence the revision rate following unicondylar knee replacement: an analysis of 23,400 medial cemented unicondylar knee replacements. J Bone Joint Surg Am 95:702-709

3. Bali K, Walker P, Bruce W (2012) Custom-fit total knee arthroplasty: our initial experience in 32 knees. J Arthroplasty 27:1149-1154

4. Bell SW, Stoddard J, Bennett C, London NJ (2014) Accuracy and early outcomes in medial unicompartmental knee arthroplasty performed using patient specific instrumentation. Knee 21(Suppl 1):S33-S36

5. Bruni D, Iacono F, Russo A, Zaffagnini S, Marcheggiani Muccioli GM, Bignozzi S et al (2010) Minimally invasive unicompartmental knee replacement: retrospective clinical and radiographic evaluation of 83 patients. Knee Surg Sports Traumatol Arthrosc 18:710-717

6. Chau R, Gulati A, Pandit H, Beard DJ, Price AJ, Dodd CA et al (2009) Tibial component overhang following unicompartmental knee replacement-Does it matter? Knee 16:310-313

7. Chauhan SK, Scott RG, Breidahl W, Beaver RJ (2004) Computer-assisted knee arthroplasty versus a conventional jig-based technique. A randomised, prospective trial. J Bone Joint Surg Br 86:372-377

8. National Joint Registry for England, Wales and Northern Ireland (2016) 13th annual report. http://www.njrcentre.org.uk/njrcentre/Portals/0/Documents/England/Reports/13th\%20Annual\%20 Report/07950\%20NJR\%20Annual\%20Report\%202016\%20 ONLINE\%20REPORT.pdf. Accessed 24 June 2017

9. Dervin GF, Carruthers C, Feibel RJ, Giachino AA, Kim PR, Thurston PR (2011) Initial experience with the oxford unicompartmental knee arthroplasty. J Arthroplasty 26:192-197

10. Epinette JA, Brunschweiler B, Mertl P, Mole D, Cazenave A, French Society for $\mathrm{H}$ et al (2012) Unicompartmental knee arthroplasty modes of failure: wear is not the main reason for failure: a multicentre study of 418 failed knees. Orthop Traumatol Surg Res 98:S124-S130

11. Fitz W (2009) Unicompartmental knee arthroplasty with use of novel patient-specific resurfacing implants and personalized jigs. J Bone Joint Surg Am 91(Suppl 1):69-76

12. Goodfellow J, O'Connor J, Dodd CA, Murray DW (2006) Unicompartmental arthroplasty with the Oxford knee. Oxford University Press, Oxford, pp 171-184 
13. Gulati A, Chau R, Simpson DJ, Dodd CA, Gill HS, Murray DW (2009) Influence of component alignment on outcome for unicompartmental knee replacement. Knee 16:196-199

14. Hamilton WG, Ammeen D, Engh CA Jr., Engh GA (2010) Learning curve with minimally invasive unicompartmental knee arthroplasty. J Arthroplasty 25:735-740

15. Jaffry Z, Masjedi M, Clarke S, Harris S, Karia M, Andrews B et al (2014) Unicompartmental knee arthroplasties: robot vs. patient specific instrumentation. Knee 21:428-434

16. Jung KA, Kim SJ, Lee SC, Hwang SH, Ahn NK (2010) Accuracy of implantation during computer-assisted minimally invasive Oxford unicompartmental knee arthroplasty: a comparison with a conventional instrumented technique. Knee 17:387-391

17. Kerens B, Schotanus MGM, Boonen B, Kort NP (2015) No radiographic difference between patient-specific guiding and conventional Oxford UKA surgery. Knee Surg Sport Trans A 23:1324-1329

18. Koeck FX, Beckmann J, Luring C, Rath B, Grifka J, Basad E (2011) Evaluation of implant position and knee alignment after patient-specific unicompartmental knee arthroplasty. Knee 18:294-299

19. Kotela A, Kotela I (2014) Patient-specific computed tomography based instrumentation in total knee arthroplasty: a prospective randomized controlled study. Int Orthop 38:2099-2107

20. Krishnan SP, Dawood A, Richards R, Henckel J, Hart AJ (2012) A review of rapid prototyped surgical guides for patient-specific total knee replacement. J Bone Joint Surg Br 94:1457-1461

21. Liddle AD, Pandit H, Judge A, Murray DW (2016) Effect of surgical caseload on revision rate following total and unicompartmental knee replacement. J Bone Joint Surg Am 98:1-8

22. Lindstrand A, Stenstrom A, Ryd L, Toksvig-Larsen S (2000) The introduction period of unicompartmental knee arthroplasty is critical: a clinical, clinical multicentered, and radiostereometric study of 251 Duracon unicompartmental knee arthroplasties. J Arthroplasty 15:608-616

23. Lisowski LA, van den Bekerom MP, Pilot P, van Dijk CN, Lisowski AE (2011) Oxford phase 3 unicompartmental knee arthroplasty: medium-term results of a minimally invasive surgical procedure. Knee Surg Sports Traumatol Arthrosc 19:277-284

24. Murray DW, Fitzpatrick R, Rogers K, Pandit H, Beard DJ, Carr AJ et al (2007) The use of the Oxford hip and knee scores. J Bone Joint Surg Br 89:1010-1014

25. Noble JW Jr, Moore CA, Liu N (2012) The value of patientmatched instrumentation in total knee arthroplasty. J Arthroplasty 27:153-155

26. Ollivier M, Parratte S, Lunebourg A, Viehweger E, Argenson JN (2016) The John Insall Award: no functional benefit after unicompartmental knee arthroplasty performed with patient-specific instrumentation: a randomized trial. Clin Orthop Relat Res 474:60-68
27. Ollivier M, Tribot-Laspiere Q, Amzallag J, Boisrenoult P, Pujol $\mathrm{N}$, Beaufils $\mathrm{P}$ (2016) Abnormal rate of intraoperative and postoperative implant positioning outliers using "MRI-based patientspecific" compared to "computer assisted" instrumentation in total knee replacement. Knee Surg Sports Traumatol Arthrosc 24:3441-3447

28. Pandit H, Hamilton TW, Jenkins C, Mellon SJ, Dodd CA, Murray DW (2015) The clinical outcome of minimally invasive Phase 3 Oxford unicompartmental knee arthroplasty: a 15-year follow-up of 1000 UKAs. Bone Joint J 97(B):1493-1500

29. Price AJ, Svard U (2011) A second decade lifetable survival analysis of the Oxford unicompartmental knee arthroplasty. Clin Orthop Relat Res 469:174-179

30. Rees JL, Price AJ, Beard DJ, Dodd CA, Murray DW (2004) Minimally invasive Oxford unicompartmental knee arthroplasty: functional results at 1 year and the effect of surgical inexperience. Knee 11:363-367

31. Renson L, Poilvache P, Van den Wyngaert H (2014) Improved alignment and operating room efficiency with patient-specific instrumentation for TKA. Knee 21:1216-1220

32. Robertsson O, Knutson K, Lewold S, Lidgren L (2001) The routine of surgical management reduces failure after unicompartmental knee arthroplasty. J Bone Joint Surg Br 83:45-49

33. Thienpont E, Bellemans J, Delport H, Van Overschelde P, Stuyts B, Brabants K et al (2013) Patient-specific instruments: industry's innovation with a surgeon's interest. Knee Surg Sports Traumatol Arthrosc 21:2227-2233

34. van Leeuwen JA, Rohrl SM (2017) Patient-specific positioning guides do not consistently achieve the planned implant position in UKA. Knee Surg Sports Traumatol Arthrosc 25:752-758

35. Vardi G, Strover AE (2004) Early complications of unicompartmental knee replacement: the Droitwich experience. Knee 11:389-394

36. Volpi P, Prospero E, Bait C, Cervellin M, Quaglia A, Redaelli A et al (2015) High accuracy in knee alignment and implant placement in unicompartmental medial knee replacement when using patient-specific instrumentation. Knee Surg Sports Traumatol Arthrosc 23:1292-1298

37. Watters TS, Mather RC III, Browne JA, Berend KR, Lombardi AV Jr., Bolognesi MP (2011) Analysis of procedure-related costs and proposed benefits of using patient-specific approach in total knee arthroplasty. J Surg Orthop Adv 20:112-116

38. Yan CH, Chiu KY, Ng FY, Chan PK, Fang CX (2015) Comparison between patient-specific instruments and conventional instruments and computer navigation in total knee arthroplasty: a randomized controlled trial. Knee Surg Sports Traumatol Arthrosc 23:3637-3645 